\title{
Recuperação ambiental da cascalheira do Parque Recreativo Sucupira (Planaltina, Distrito Federal, Brasil)*
}

\section{Alexandre Nascimento de Almeida', Nikolas Gebrim Rodrigues², Humberto Angelo ${ }^{3}$}

${ }^{1}$ Faculdade UnB de Planaltina. Universidade de Brasília (FUP/UnB). Área Universitária n. 1. Vila Nossa Senhora de Fátima. Planaltina-DF. Brasil. (CEP 73300-000). E-mail: alexalmeida@unb.br.

${ }^{2}$ Faculdade UnB de Planaltina. Universidade de Brasília (FUP/UnB). Área Universitária n. 1. Vila Nossa Senhora de Fátima. Planaltina-DF. Brasil. (CEP 73300-000).

${ }^{3}$ Engenheiro Florestal. Professor Dr. Departamento de Engenharia Florestal. Faculdade de Tecnologia. Universidade de Brasília (EFL/FT/UnB). Brasília-DF (CEP 70910-900).

Resumo. A construção do campus da Universidade de Brasília (UnB) no Município de Planaltina (FUP) ocorreu em uma Área Preservação Ambiental - APA do Cerrado, tendo a FUP assumido o compromisso de recuperar uma área degrada por extração de cascalho no Parque Recreativo Sucupira para obter a sua licença ambiental. Embora a FUP tenha sido inaugurada há 10 anos a cascalheira ainda não foi recuperada, assim, os objetivos do presente trabalho são elaborar uma proposta de recuperação para a cascalheira do Parque Recreativo Sucupira e estimar o custo presente dessa atividade. A partir do diagnóstico da área, em conjunto com referências bibliográficas, constatou-se que a recuperação da cascalheira demanda uma rigorosa intervenção no preparo do solo e a necessidade de um plantio adensado de mudas, estimando um custo de recuperação em torno de $\mathrm{R} \$ 50$ mil (cinquenta mil reais) por hectare.

Palavras-chaves: Cerrado; Parque Ecológico; Recuperação de Áreas Degradadas.

\begin{abstract}
Environmental recover of the gravel pit in the Sucupira Recreational Park (Planaltina, Distrito Federal, Brasil). The construction of the UnB Campus in Planaltina (FUP), Federal District, Brazil, was carried out in an Environmental Preservation Area (EPA) in the Cerrado, and the FUP was committed to restoring the area degraded by gravel extraction, inside the Sucupira Recreational Park, to obtain its environmental license. Although the FUP was inaugurated 10 years ago, the gravel pit has not yet been recovered. Thus, this study aimed to formulate a recovery project for the gravel pit in the Sucupira Recreational Park and estimate the current cost of this activity. From the diagnosis of the area through bibliographic references, it was found that the recovery of gravel needs a rigorous intervention in soil preparation and dense planting seedlings, estimating a cost recovery of about R\$ 50,000 per hectare.
\end{abstract}

Recebido: 31/03/2017

Aceito: $14 / 06 / 2017$

Publicado: 30/06/2017

Acesso Aberto Artigo completo

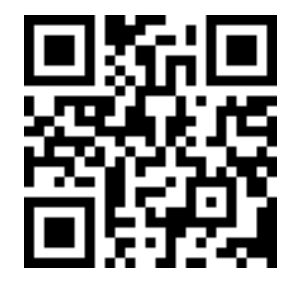

ORCID

(1) 0000-0002-9113-0729

Alexandre Nascimento de Almeida

(b) 0000-0002-1077-2958

Nikolas Gebrim Rodrigues

(1) 0000-0002-2374-6484

Humberto Angelo

Keywords: Cerrado; Ecological Park; Recovery of Degraded Areas.

Parte do trabalho de conclusão de Curso de Bacharelado em Gestão Ambiental, do segundo autor, apresentado à FUP/UnB, em 2016. 


\section{Introdução}

Com o intuito de ampliar e democratizar as vagas no ensino superior, a Universidade de Brasília (UnB) ampliou suas instalações por meio da construção de três campi em municípios na periferia de Brasília, Planaltina, Ceilândia e Gama.

Diante da possibilidade da construção da Faculdade UnB de Planaltina (FUP) causar impacto ambiental significativo, a UnB assumiu o compromisso de elaborar um plano de recuperação para uma área degradada de uma antiga cascalheira que se encontra dentro da Poligonal do Parque Recreativo Sucupira, compromisso esse assumido em 2006 e, passados 10 anos, ainda não realizado.

O compromisso assumido pela UnB para recuperação do Parque Sucupira não se configurou legalmente como uma condicionante para a obtenção da licença ambiental, sendo acordada por meio de procedimento específico com o Instituto Brasília Ambiental (IBRAM), responsável pela outorga da licença ambiental da FUP, através do Processo ${ }^{\circ}$ 190.000.422/2000.

A demora ou o não cumprimento de compromissos ambientais não é privilégio da UnB, embora o não cumprimento dessas obrigações pode ser motivo de aplicação de multas e ajuizamento de ação civil pública. Especificamente em projetos de mineração, a legislação brasileira exige a apresentação de um Plano de Recuperação de Área Degrada (PRAD) para a obtenção da licença ambiental. Entretanto, cerca de 90\% dos PRAD's existentes nos processos de licenciamento de jazidas no Distrito Federal não foram executados, ou seja, as mineradoras se comprometem em recuperar a área após o fechamento da mina e não o fazem (Leite e Castro, 2002).

A recuperação do Parque Recreativo Sucupira proporciona ganhos diretos e indiretos para a comunidade da FUP. Indiretamente, o benefício da recuperação do parque ocorre por meio dos seus serviços ambientais como, por exemplo, o controle de pragas e doenças, o abastecimento do lençol freático, a melhoria do microclima, a proteção e preservação do solo, entre outros. Diretamente, dado que os cursos da FUP (Ciências Naturais, Gestão Ambiental, Gestão do Agronegócio e Licenciatura em Educação do Campo) são orientados para uma temática com um grande apelo ambiental, o Parque Recreativo Sucupira pode ser um ambiente de várias ações do campus, tanto em aulas práticas como em atividades de pesquisa e extensão. Como exemplos de pesquisas já realizadas no Parque Recreativo Sucupira podem-se exemplificar os trabalhos de Cavalcante (2010), Bernandes (2013) e Oliveira (2014).

O objetivo do trabalho é contribuir como uma referência para a recuperação de área degradada por mineração de cascalho, em especifico pretende-se propor um projeto de recuperação de área degradada, detalhando todas as atividades e mensurando todos os insumos necessários para a sua implantação; e determinar os custos ao longo do processo de recuperação e estimar o seu valor presente.

\section{Material e Métodos}

\section{Área do projeto de recuperação}

O Parque Recreativo Sucupira foi criado pela Lei Distrital ${ }^{\circ} 1.318$, de 23 de dezembro de 1996 (Distrito Federal, 1996) e, embora tenha sido inaugurado em $1^{\circ}$ de junho 2014, ainda não foi implementado em sua plenitude, sendo pouco conhecido e explorado em atividades de lazer, pesquisa e esporte. De acordo com a Lei Complementar $\mathrm{n}^{0}$ 265, 14 de dezembro de 1999 (Distrito Federal, 1999), o Parque Recreativo Sucupira é caracterizado como uma unidade de conservação de uso sustentável e, mais especificamente, um parque de uso múltiplo. Os parques de uso múltiplo devem estar situados em centros urbanos, em local de fácil acesso à população, tendo como objetivos conservar o ambiente natural, recuperar áreas degradadas, estimular a educação ambiental local e realizar atividades de lazer em contato com a Natureza (IBRAM, 2016).

O Parque Recreativo Sucupira possui $250.000 \mathrm{~m}^{2}$ (25 ha) e ocupa área remanescente da Fazenda Sucupira, estando localizado no perímetro urbano da Região 
Administrativa de Planaltina, no Distrito Federal, entre o Setor Norte e a Vila Nossa Senhora de Fátima e a região oeste do prolongamento da Avenida Gomes Rabelo. O Parque localiza-se na Sub-Bacia do
Ribeirão Mestre D’Armas e na Bacia do Rio São Bartolomeu e possui uma fitofisionomia de Campo Cerrado, resultado da degradação da área (Figura 1).

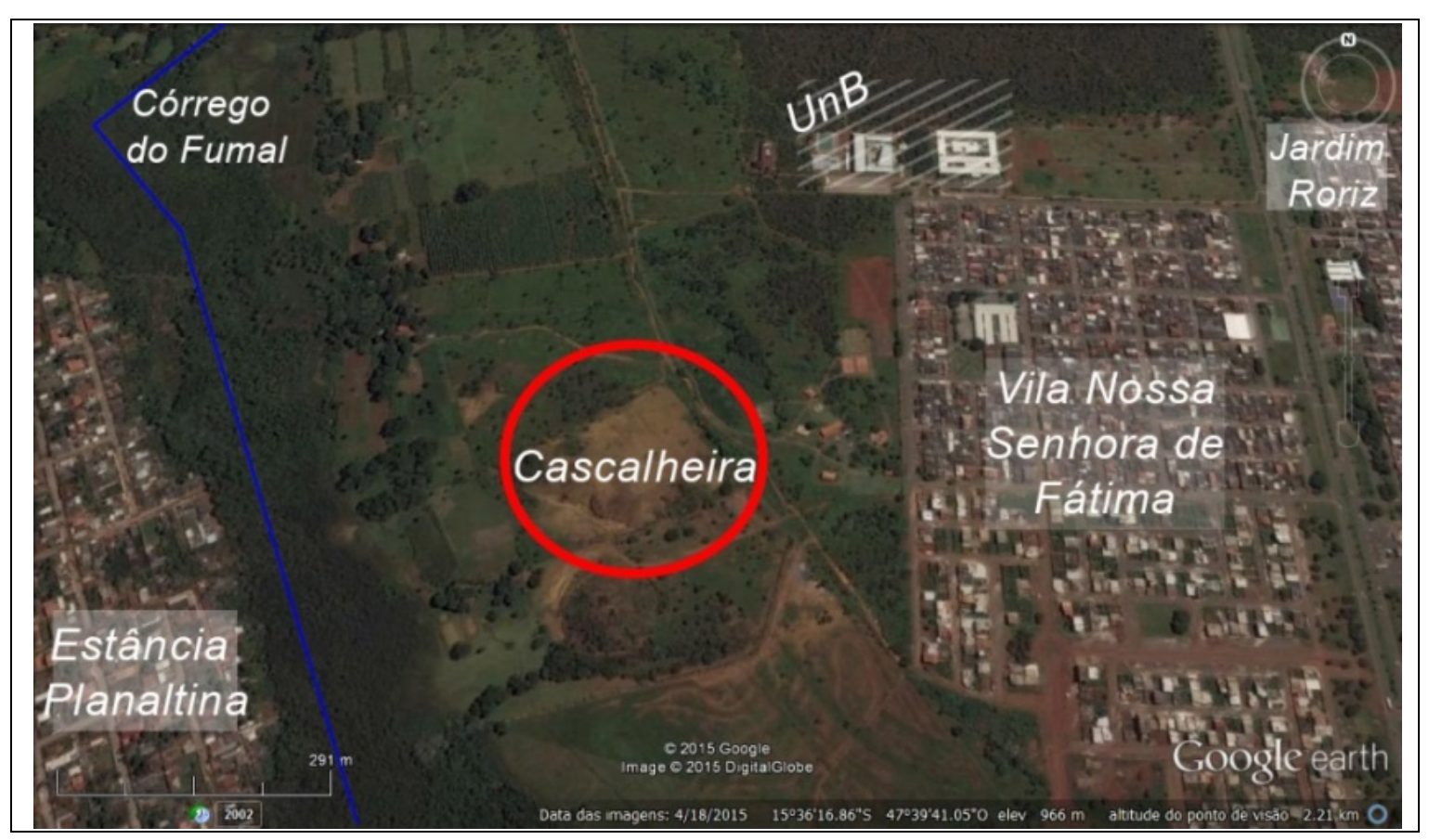

Figura 1. Áreas de influencia direta da cascalheira. Fonte: Google Earth.

As áreas circunvizinhas do parque são:

- Bairro Jardim Roriz: localiza-se a $890 \mathrm{~m}$ da cascalheira, existe desde a década de 1990 e atualmente tem uma população de aproximadamente 20 mil habitantes;

- Vila Nossa Senhora de Fátima: existe desde 1993 e tem uma população estimada de 2.100 habitantes;

- Estância Planaltina: a 300 m da cascalheira, inserida no Setor Habitacional Mestre D'Armas e próxima à Rodovia DF-128 e à Rodovia BR-020. Atualmente, residem nessa área cerca de 27 mil habitantes, que são atendidos por rede de energia elétrica, rede de água e parcialmente por rede de esgoto e pavimentação asfáltica. A maioria dos ocupantes desse parcelamento são pessoas com baixo poder aquisitivo;

- Faculdade UnB Planaltina: a 600 m da cascalheira, a FUP conta com três prédios e uma área construída de $6.562 \mathrm{~m}^{2}$, o que totalizou um investimento de mais de 11 milhões de reais.

- Cascalheira: que se encontra no interior do Parque Recreativo Sucupira possui uma área total de 5,37 ha e está no local há pelo menos 15 anos sem atividade de mineração e em situação completamente degradada (Figura 2). Á área da cascalheira é plana, o clima predominante é o Tropical de Savana - AW com uma temperatura média anual é de $20^{\circ} \mathrm{C}$ e a precipitação anual na área varia de 1.200 a 1600 mm (IBGE, 2016). 


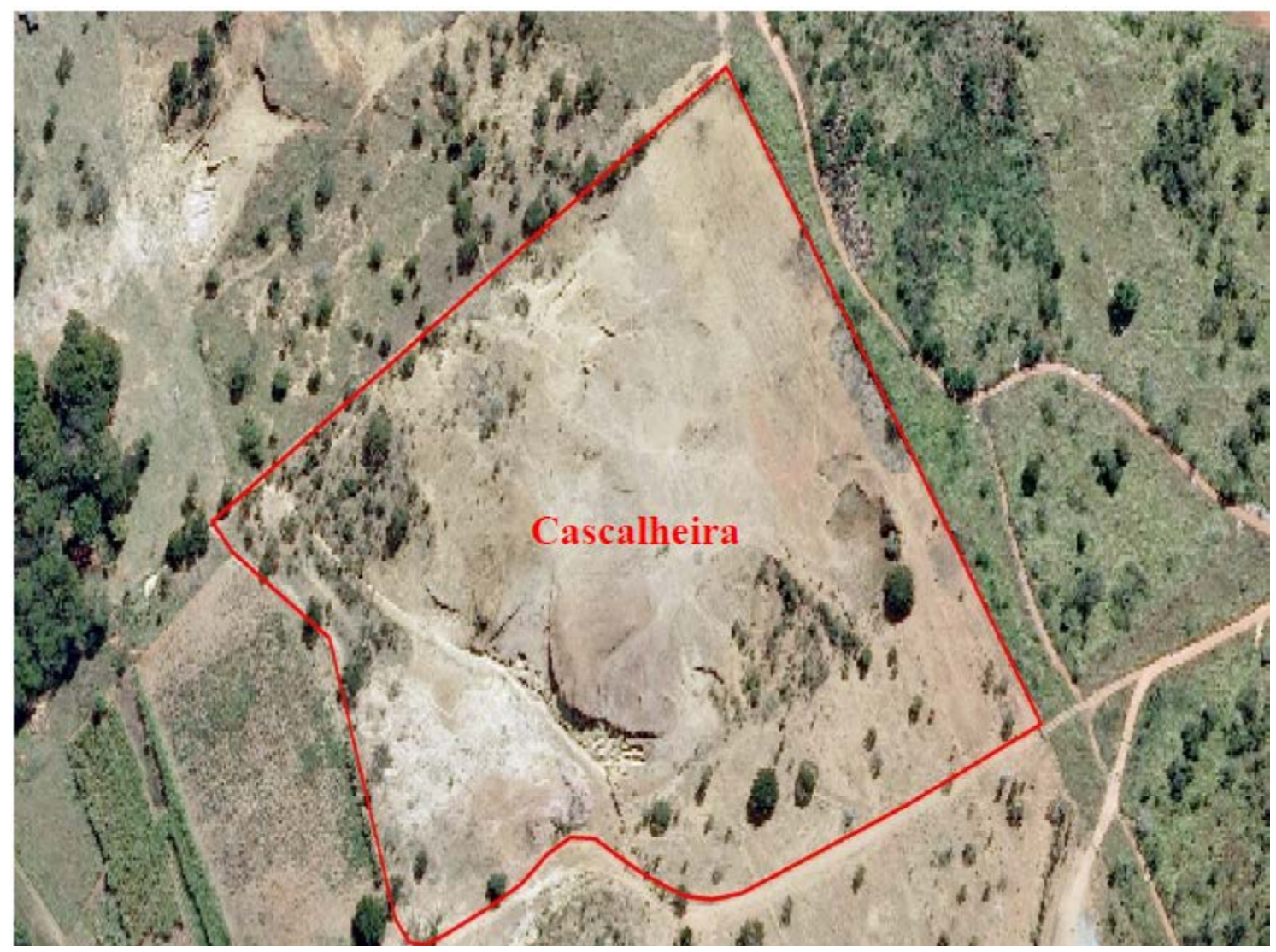

Figura 2. Cascalheira do Parque Recreativo Sucupira.

\section{Projeto de recuperação de área degradada}

A identificação da melhor técnica de recuperação da área, bem como, o estabelecimento de todas as atividades necessárias para recuperação, inclusive a mensuração dos insumos necessários, considerou um diagnóstico estruturado da área, que é composto por uma completa descrição e análise dos recursos ambientais e suas interações, caracterizando a situação ambiental da área após considerar o meio físico e biótico. As principais atividades do diagnóstico incluem a avaliação de aspectos como: estado de conservação do solo, presença de vegetação arbórea nativa remanescente na área ou nas proximidades, topografia, regime hídrico, proximidade de curso d’água e histórico de uso da área (Martins, 2009).

A partir do diagnóstico da área foram hierarquizadas as atividades a serem executadas, bem como mensurado os insumos necessários para a sua realização, de acordo com Furtini Neto et al. (2004), Gonçalves et al. (2004), Kageyama e Gandara (2004), Côrrea (2007) e Martins (2009).

Valor presente dos custos de
recuperação
Devido a algumas atividades em
um projeto de recuperação de áreas
degradadas ocorrerem ao longo do tempo é
necessário utilizar o valor presente dos seus
custos para, então, contabilizar o custo total


do projeto (Casarotto Filho e Kopittke, 2010). A primeira etapa do método consistiu na elaboração do fluxo de caixa, determinado o custo de todas as atividades por semestre durante seis anos, que é o período total do projeto.

De acordo com Casarotto Filho e Kopittke (2010), o cálculo do valor presente dos custos de recuperação é feito por meio da Equação 1.

$$
\mathrm{VPCR}=\sum_{t=1}^{n} \frac{C_{t}}{(1+i)^{t}}
$$

Em que:

VPCR $=$ Valor Presente do Custo de Recuperação período $t$

Ct $=$ Custo de cada atividade no

$\mathrm{i}=$ taxa de desconto

$\mathrm{t}=$ período (semestres)

No Brasil, esta taxa de desconto se refere à Taxa de Juros de Longo Prazo (TJLP), cujo valor médio dos últimos cinco anos situou-se em torno de $5,7 \%$ ao ano (BNDES, 2016). Transformando a taxa anual de 5,7\% para a uma taxa equivalente em regime composto tem-se o valor de $2,46 \%$ ao semestre.

\section{insumos}

Levantamento de preços dos

As cotações de preços de materiais e insumos tomaram como base a Lei $n^{\circ}$ 8.666/1993 (Brasil, 1993), que institui normas para licitações e contratos da administração pública. Para tanto, realizaram-se pesquisas de mercado com a cotação de três preços diferentes para o mesmo insumo em lojas do Distrito Federal e Goiás, entre novembro de 2015 e março de 2016.

Para a cotação de preços, também foram consultados PRAD's de trabalhos executados pelo o governo distrital (CEB, 2015) e empresas privadas (EMBRAGEA, 2014). Assim como o site de classificados do agronegócio e portais de pesquisa e comparação de preços, como MF Rural (http://www.mfrural.com.br), Classificado Agrícola (http://www.classificadosagrico las.com.br), AgroDigital (http://www.agro digital.com.br), Campovita (http://www. campovita.com.br) e Mercado Livre (http://www.mercadolivre.com.br). Também se realizou levantamento de preços em estabelecimento comercial de Brasília (DF), Planaltina (DF) e Formosa-GO, como a Casa da Lavoura, a Loja do Fazendeiro Produto Agrícola, a Agropecuária da Feira, a Loja do Fazendeiro, a AgroCampo e a AgroRural.

$\mathrm{Na}$ escolha do insumo foi levada em conta o preço, a disponibilidade, a qualidade e o frete do produto. Para facilitar o entendimento, o preço de frete foi diluído nos valores dos insumos.

\section{Resultados e discussão}

$\begin{aligned} & \text { Plano de recuperação da antiga } \\ & \text { cascalheira do Parque Recreativo } \\ & \text { Sucupira }\end{aligned}$
O projeto de recuperação da
cascalheira do Parque Recreativo Sucupira foi divido em três fases: 1) manutenção, 2) implementação, e 3) monitoramento, totalizando seis anos de projeto divididos em dois anos para cada fase.

Devido à área se encontrar altamente degradada torna-se necessário uma profunda intervenção no preparo e correção inicial do solo, sendo previstos métodos de subsolagem e escarificação do material exposto e posterior adubação verde. A profundidade prevista para a escarificação e subsolagem são de 30 e $50 \mathrm{~cm}$, respectivamente. Segundo Côrrea (2007), em áreas mineradas, a capacidade de infiltração de água dos horizontes expostos cai para cerca de $10 \%$ dos valores originalmente existentes no solo coberto por vegetação nativa. Ainda conforme o autor, a escarificação triplica a capacidade de infiltração de substratos minerados e compactados.

Antes da adubação verde, será realizado o combate de formigas cortadeiras dentro da área a ser recuperada e no perímetro de até $100 \mathrm{~m}$ de adjacência. O método a ser empregado é o de isca granulada, por ser mais seguro na aplicação e menos tóxico ao ambiente. Um problema comum desse método é a perda das iscas 
pelo contato com umidade, para evitar esse problema, a aplicação das iscas é prevista para ocorrer nos meses de baixa pluviosidade: julho, agosto e setembro, conforme sugestões de Martins (2009).

Após a subsolagem e combate a formigas, é previsto o plantio de leguminosas consorciadas com gramíneas (adubação verde), utilizando o amendoim forrageiro (Arachis pintoi Belmonte), o feijão guandu (Cajanus cajan), o capim jaraguá (Hyparrbenia rufa), a grama babatais (Paspalum notatum), a crotalária (Crotalaria spp). Portanto, o preparo do solo demandará o prazo de um ano antes do início do plantio final de mudas.

O consórcio de gramíneas e leguminosas na adubação verde é quase sempre a opção escolhida para compor o estrato rasteiro em projetos de revegetação. As gramíneas produzem grande biomassa aérea e subterrânea (raízes), que evitam erosão e aumentam o teor de carbono do "solo em processo de construção". As leguminosas são escolhidas por causa das bactérias do gênero Rhizobium, que habitam suas raízes e fixam nitrogênio do ar, adubando o substrato com esse nutriente (Corrêa, 2007).

Após o preparo do solo, o plantio de mudas vai considerar as principais espécies do Cerrado presentes no Parque Recreativo Sucupira, privilegiando espécies frutíferas para atrair a fauna e, assim, contribuir com a dispersão de sementes e potencializar a recuperação da área. Entre as espécies com alto potencial para atrair a fauna se destacam: a embaúba (Cecropia sp), o ingá (Inga sp), o baru (Dipteryx alata), a mamacadela (Brosimum gaudichaudii), o pequi (Caryocar brasiliense), a guariroba (Campomanesia xanthocarpa) e a cagaita (Campomanesia xanthocarpa). O período de plantio deve ser realizado no início da estação chuvosa, previsto para ocorrer nos meses de outubro e novembro.

Devido ao solo da área a ser recuperada estar compacto e completamente degradado é proposto um coveamento para plantio um pouco maior do que o normal, propondo covas para todas as mudas com as dimensões de $45 \times 45 \times 60 \mathrm{~cm}$, conforme sugestão de Martins (2009).

O plantio das mudas em campo será por meio da combinação das espécies em grupos de plantio, visando à implantação das espécies nos estágios finais de sucessão (secundarias tardias e clímax) conjuntamente com espécies nos estágios iniciais de sucessão (pioneiras e secundárias iniciais). Esse método resulta em uma gradual substituição de espécies de diferentes grupos ecológicos no tempo, não havendo a preocupação de se plantarem espécies que forneçam sombra para as outras ou que cresçam muito rápido. Conforme recomendações de Kageyama e Gandara (2004), em geral, plantam-se entre $50 \%$ e $60 \%$ de espécies pioneiras e cerca de $40 \%$ de espécies secundárias tardias e clímax. O espaçamento escolhido entre as mudas foi

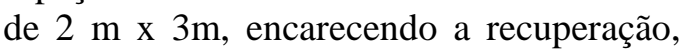
porém proporcionando uma ampla cobertura da área. Com esse espaçamento o número total de mudas previstas para serem plantadas foi de 8.950 .

As principais espécies pioneiras consideradas no projeto são a macaúba (Acrocomia aculeata), o angico-vermelho (Anadenanthera macrocarpa), o indaiá (Attalea geraensis) e a unh-de-vaca (Bauhinia rufa). Dentre as espécies secundárias tardias e clímax destacam-se o butiá-roxo (Butia purpurascens), a mamacadela (Brosimum gaudichaudii), o pequi (Caryocar brasiliense), a gabiroba (Campomanesia pubescens), o mercúrio (Erythroxylum suberosum), a pera-do-cerrado (Eugenia klotzchiana), entre outras.

Para a adubação, considerou-se a aplicação de $100 \mathrm{~g}$ de adubo químico NPK 4:14:8, mais $20 \mathrm{~L}$ de adubo orgânico (esterco de curral) e $100 \mathrm{~g}$ de calcário, por cova. Não foi feito análise química no solo devido ao seu baixo custo/benefício, pois, conforme Martins (2009), de maneira geral, em revegetação, o fósforo é colocado em maior quantidade que os outros elementos, por ser aquele presente em menor concentração no solo quando se trata de áreas altamente degradadas como, por exemplo, as de mineração. Portanto, devido 
às diversas referências sobre recuperação de áreas de mineração, assumiu-se que a correção do solo pode prescindir de análise química.

Segundo Corrêa (2007), adubos orgânicos e fertilizantes químicos têm funções específicas e sinérgicas, que se complementam. Assim, a combinação deles têm mostrado ser a melhor prática para a recuperação de solos degradados. De acordo com Leite et al. (1992), a revegetação de locais minerados no Cerrado não é possível sem a adição de grandes quantidades de matéria orgânica aos seus substratos.

Em relação à aplicação de calcário, Lopes (1994) afirma que "adubar solo ácido é jogar dinheiro fora”, pois nutrientes não são absorvidos pelas plantas sob condições ácidas de solos e substratos. A acidez de substratos pode ser contornada por meio da calagem, a adição de calcário. A calagem corrige a acidez e a toxicidade por alumínio e manganês, aumenta a absorção vegetal de vários nutrientes (fósforo, potássio e outros) e fornece cálcio $(\mathrm{Ca})$ e magnésio $(\mathrm{Mg})$ para as plantas.

A demanda das plantas por nutrientes varia de acordo com a espécie, a estação do ano e a fase de crescimento (Siqueira et al., 1995). Ela é mais intensa nos estágios iniciais de desenvolvimento (Furtini Neto et al., 2004) e, segundo Gonçalves et al. (2004), após a planta atingir a idade adulta é improvável obter respostas no seu desenvolvimento devido ao incremento de fertilizantes no solo. Ainda segundo Gonçalves et al. (2004), a fertilização deve ser entendida como um mecanismo de aceleração do crescimento de vegetais. Após essa fase de aceleração, as plantas crescerão de acordo com as limitações impostas pelas condições locais.

Para evitar a mortalidade das mudas após a implementação do projeto, são previstas ações de manutenção para evitar perdas decorrentes de possíveis ataques de formigas, deficiência de nutrientes no solo, competição de mudas com gramíneas, deficiência hídrica e incêndio. O período de manutenção é previsto para ocorrer durante o terceiro e quarto ano do projeto, continuando com tratos silviculturais e manutenção de aceiros durante o período de monitoramento, bem como, o replantio de mudas e combate de pragas na fase de monitoramento.

Em conjunto com a realização da recuperação da cascalheira, a partir do segundo semestre do terceiro ano do projeto, é previsto a realização de um projeto de educação ambiental, tendo em vista que a área a ser recuperada se localiza ao lado de um campus da UnB em que os seus cursos são relacionados com a área de ciências da vida e da terra.

Todas as atividades do projeto, nas fases de implantação, manutenção e monitoramento, encontram-se na Tabela 1.

\section{Custo presente líquido do plano de recuperação de áreas degradadas}

Para uma melhor analise do projeto, que tem duração de seis anos, dividiu-se o fluxo de caixa em doze semestres, apresentando o custo das atividades nas três grandes fases: implementação, manutenção e monitoramento (Figura 3). A quantidade dos insumos utilizados, bem como o detalhamento de todos os custos do projeto se encontram nos Anexos 1 e 2.

O custo presente total para recuperar a cascalheira do Parque Recreativo Sucupira foi estimado em R\$ 271.193,54, sendo que na fase de implementação é previsto um gasto de R\$ 184.272,44 (67,95\%), na fase de manutenção de R\$ 50.134,37 (18,49\%) e na fase de monitoramento de $\mathrm{R} \$ 36.786,73$ $(13,56 \%)$. Na área total da cascalheira de 5,37 ha esse valor é equivalente a $\mathrm{R} \$$ $50.501,59 /$ ha. 
Tabela 1. Atividades do programa de recuperação da cascalheira.

\begin{tabular}{|c|c|}
\hline \multicolumn{2}{|r|}{ IMPLANTAÇÃO } \\
\hline Cercamento da área & $\begin{array}{l}\text { Isolamento da extensão revegetada com estacas de madeira e fio de } \\
\text { arame farpado. }\end{array}$ \\
\hline Sinalização da área & $\begin{array}{l}\text { Confecção e alocação de placas de aviso na área de recuperação em } \\
\text { locais estratégicos ao longo do perímetro da área de recuperação. }\end{array}$ \\
\hline Manejo de pragas & $\begin{array}{l}\text { Controle de formigas e cupins por meio de iscas com substâncias e } \\
\text { quantidades previamente aprovadas segunda as normas vigentes. }\end{array}$ \\
\hline Preparo do solo & $\begin{array}{l}\text { Subsolagem e escarificação do material exposto, utilizando um } \\
\text { maquinário de leve porte. Sulcamento: Abertura de sulcos utilizando } \\
\text { trator com sulcador para o plantio das mudas em linhas, distantes } 3 \\
\text { metros uma da outra. }\end{array}$ \\
\hline Adubação verde & Plantio de leguminosas misturado com gramíneas. \\
\hline Plantio de mudas & $\begin{array}{l}\text { O plantio deve ser realizado preferencialmente na época chuvosa, } \\
\text { evitando assim o usa da irrigação, que encarece o plantio. }\end{array}$ \\
\hline Coroamento & $\begin{array}{l}\text { Limpeza manual da vegetação herbácea e subarbustiva exótica no } \\
\text { entorno do local do plantio das mudas e redução da densidade da } \\
\text { vegetação ao longo da linha de plantio, focando mais na redução no } \\
\text { entorno do local. }\end{array}$ \\
\hline Tutoramento & $\begin{array}{l}\text { Fixação de tutores de bambu para suporte às mudas que também } \\
\text { servirão para a fácil localização facilitando no monitoramento. }\end{array}$ \\
\hline Calagem & Distribuição de calcário dolomítico para corrigir a acidez do solo. \\
\hline Adubação & $\begin{array}{l}\text { Adubação orgânica com esterco de animal, que tenha passado pelo } \\
\text { processo de decomposição. E a utilização adubo químico para } \\
\text { complementação como NPK. }\end{array}$ \\
\hline \multicolumn{2}{|r|}{ MANUTENÇÃO } \\
\hline Adubação de cobertura & $\begin{array}{l}\text { Adubação realizada após o plantio no início do ciclo das chuvas de } \\
30 \text { a } 90 \text { dias apos plantio. }\end{array}$ \\
\hline Replantio de mudas & $\begin{array}{l}\text { Avaliação da sobrevivência das mudas e reposição de mudas mortas } \\
\text { e replantio preferencialmente no período chuvoso para diminuir os } \\
\text { custos. }\end{array}$ \\
\hline Tratos silviculturais & $\begin{array}{l}\text { Coroamento ao final do período chuvoso, roçadas de acordo com a } \\
\text { avaliação da área e controle de pragas com iscas e roçagem. }\end{array}$ \\
\hline Prevenção de incêndios & $\begin{array}{l}\text { Controle de incêndios por meio de aceiramento; e vigilância da área } \\
\text { durante o período de seca. }\end{array}$ \\
\hline Programa de educação ambiental & $\begin{array}{l}\text { Educação ambiental por meio de distribuição de panfletos e projetos } \\
\text { para os frequentadores do parque e a população local }\end{array}$ \\
\hline \multicolumn{2}{|r|}{ MONITORAMENTO } \\
\hline Plano de Monitoramento & $\begin{array}{l}\text { Atividades de Adubação de cobertura, tratos silviculturais, e } \\
\text { prevenção de incêndios com supervisão de profissional habilitado. }\end{array}$ \\
\hline Supervisão técnica & $\begin{array}{l}\text { Acompanhamento e supervisão das atividades de implantação, } \\
\text { manutenção e monitoramento por profissional técnico e profissional } \\
\text { habilitado. }\end{array}$ \\
\hline
\end{tabular}

Segundo Corrêa (2007), os Planos de Recuperação de Área Degrada (PRAD) executados no Bioma do Cerrado variam bastante e têm sido orçados entre $\mathrm{R} \$$ $500,00 /$ ha e $\mathrm{R} \$ 15.000,00 /$ ha revegetado. $\mathrm{Na}$ literatura também são encontrados valores médios de R \$ 1.250/ha recuperado, considerando uma nova técnica inovadora da EMBRAPA (Santos e Gomes, 2012), podendo chegar até a $\mathrm{R} \$$ 40.000/ha em área completamente degradada de Mata Atlântica (Almeida et al., 2010). Segundo a Planilha de Custos para Análise de PRAD, do Instituto Brasileiro do Meio Ambiente e dos Recursos Naturais Renováveis (IBAMA), com levantamento de dados realizados no Estado do Goiás, pode-se variar de $\mathrm{R} \$ 57.048,85 / \mathrm{ha}$ a $\mathrm{R} \$$ 72,154,75/ha de área recuperada (IBAMA, 2013). 


\section{IMPLEMENTAÇÃO}

$\begin{array}{ll}1^{\circ} \text { Semestre / ano } 1 & \text { R\$ 0,00 }\end{array}$

\section{MANUNTENÇÃO}

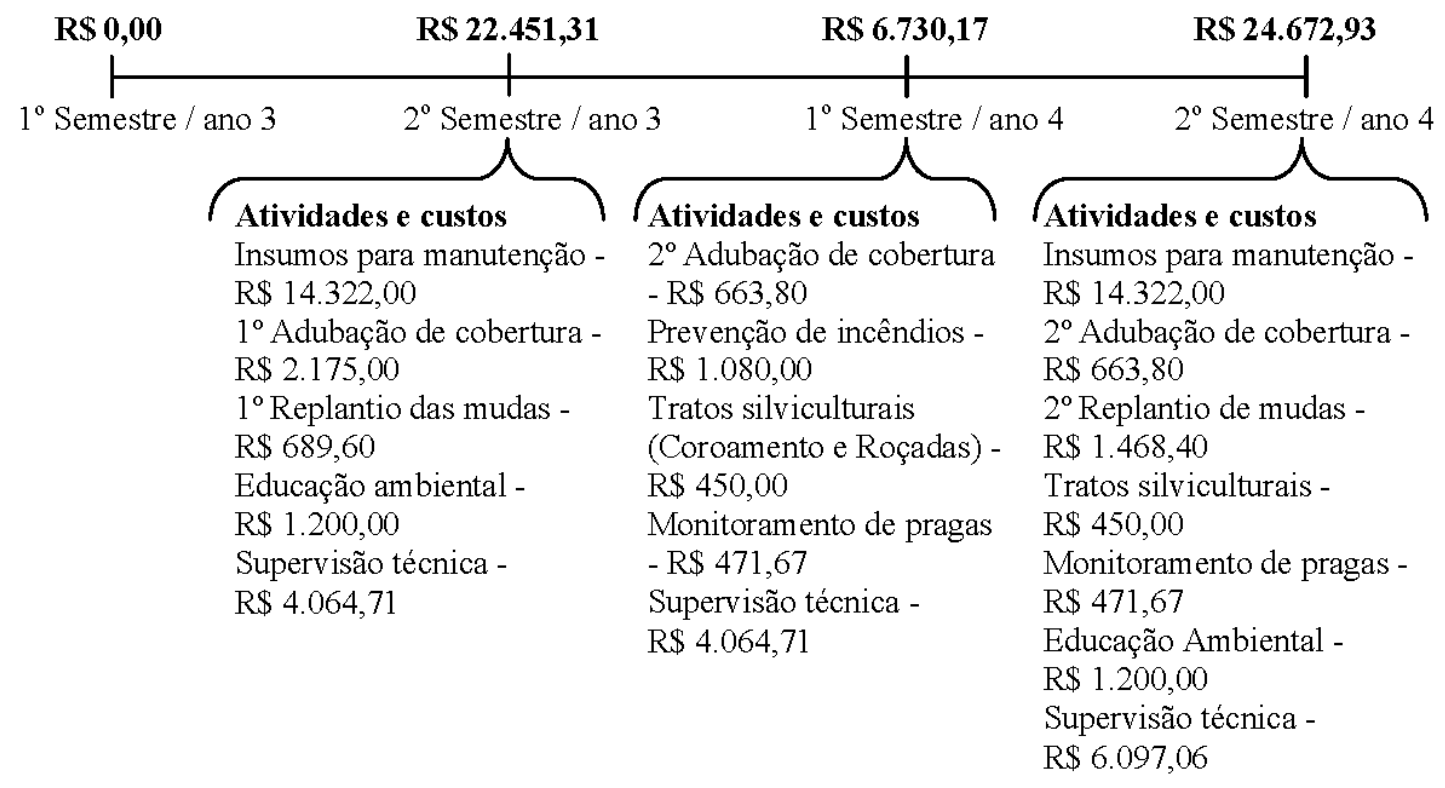

\section{MONITORAMENTO}

\begin{tabular}{|c|c|c|c|}
\hline $\mathrm{R} \$ 14.053,72$ & R\$ 4.986,37 & RS 17.053,72 & R\$ 4.986,37 \\
\hline $1^{\circ}$ Semestre / ano 5 & $2^{\circ}$ Semestre / ano 5 & $1^{\circ}$ Semestre / ano 6 & $2^{\circ}$ Semestre / ano 6 \\
\hline $\begin{array}{l}\text { Manutenção dos } \\
\text { aceiros - R\$ } 2.160,00\end{array}$ & $\begin{array}{l}\text { Tratos silviculturais - } \\
\mathrm{R} \$ 450,00\end{array}$ & $\begin{array}{l}\text { Manutenção dos } \\
\text { aceiros - R\$ 2.160,00 }\end{array}$ & $\begin{array}{l}\text { Tratos silviculturais - } \\
\mathrm{R} \$ 450,00\end{array}$ \\
\hline $\begin{array}{l}\text { Tratos silviculturais - } \\
\mathrm{R} \$ 450,00\end{array}$ & $\begin{array}{l}\text { Monitoramento de } \\
\text { pragas - R\$ 471,67 }\end{array}$ & $\begin{array}{l}\text { Tratos silviculturais - } \\
\mathrm{R} \$ 450,00\end{array}$ & $\begin{array}{l}\text { Monitoramento de } \\
\text { pragas - R\$ 471,67 }\end{array}$ \\
\hline $\begin{array}{l}\text { Monitoramento de } \\
\text { pragas - R\$ 471,67 }\end{array}$ & $\begin{array}{l}\text { Supervisão técnica - } \\
\mathrm{R} \$ 4.064,71\end{array}$ & $\begin{array}{l}\text { Monitoramento de } \\
\text { pragas - R\$ 471,67 }\end{array}$ & $\begin{array}{l}\text { Supervisão técnica - } \\
\text { R\$ 4.064,71 }\end{array}$ \\
\hline $\begin{array}{l}\text { Monitoramento do } \\
\text { plantio - R\$ } 4.875,00\end{array}$ & & $\begin{array}{l}\text { Monitoram ento do } \\
\text { plantio - R } \$ 4.875,00\end{array}$ & \\
\hline $\begin{array}{l}\text { Supervisão técnica - } \\
\mathrm{R} \$ 6.097,06\end{array}$ & & $\begin{array}{l}\text { Supervisão técnica - } \\
\mathrm{R} \$ 9.097,06\end{array}$ & \\
\hline
\end{tabular}

*Inclui-se na atividade Supervisão técnica no $1^{\circ}$ semestre do ano 1 e no $1^{\circ}$ semestre do ano 6 uma taxa de $\mathrm{R} \$ 3.000,00$ de administração do projeto.

Figura 3. Fluxo de caixa do programa de recuperação de área degradada. 
As referências do custo de recuperação de áreas degradadas ocorreram em diferentes períodos, tornando necessário a correção monetária desses valores para a sua comparação. O resultado da correção dos valores pelo Índice Geral dos Preços Disponibilidade Interna (IGP-DI), para o ano de 2015, encontra-se na Tabela 2.

Tabela 2. Custo/hectare para recuperar áreas degradadas.

\begin{tabular}{lc}
\hline Autor & $\begin{array}{c}\text { Custo/ha para 30/12/2015 } \\
\text { pelo IGP-DI (em R\$) }\end{array}$ \\
\hline Valor estimado no Parque Recreativo Sucupira & $50.501,59$ \\
Corrêa (2007) & 888,65 a $26.659,61$ \\
Santos e Gomes (2012) & $1.638,05$ \\
Almeida et al. (2010) & $61.268,48$ \\
MMA (2013) & $69.149,80$ a $87.459,90$ \\
\hline
\end{tabular}

Conforme a Tabela 1 , percebe-se uma grande diferença entre os custos de recuperação estimados com os calculados por Corrêa (2007) e Santos e Gomes (2012). Os motivos para o menor custo calculado por esses autores devem-se ao menor grau de degradação da área recuperada, ao uso de técnicas de recuperação mais baratas como, por exemplo, o uso de sementes ao invés de mudas, essa é um técnica de recuperação mais lenta e apropriada para situações com menor grau de degradação; a subestimação de alguns custos, principalmente, os custos com honorários profissionais, ferramentas e combustíveis.

Por outro lado, os custos apontados por Almeida et al. (2010) e MMA (2013) estiveram mais próximas dos valores encontrados, sugerindo um custo acima de R\$ $50 \mathrm{mil} /$ ha para a recuperação efetiva de uma área degradada.

$\mathrm{Na}$ Figura 4 pode-se verificar que os maiores custos do projeto concentram-se na fase de implantação devido à compra de mudas nativas do cerrado e a recuperação física e química do solo, pois a área a ser recuperada se encontra com um elevado nível de degradação. Vale destacar que os gastos com supervisão técnica e com a compra de mudas nativas do Bioma Cerrado representaram um custo de $\mathrm{R} \$$ 94.270,00 e R\$53.700,00, respectivamente, ou seja, mais da metade do custo total do projeto. Esses custos podem ser barateados em caso de uma parceira com a FUP, pois a faculdade conta com professores e alunos capazes de montar um viveiro para a produção das mudas necessárias, bem como, desempenhar a função de supervisão técnica do projeto.

Por se tratar de uma recuperação de uma área degradada dentro do Parque Recreativo Sucupira, o projeto também poderia contar com apoio de órgãos governamentais da Região Administrativa de Planaltina e do IBRAM, que são as instituições responsáveis pela administração do Parque Recreativo Sucupira. Essa parceria poderia reduzir os custos com tratos silviculturais, mão de obra para plantio, adubação e prevenção de incêndio. Além disso, resolveria a obrigação da UnB com o referido órgão ambiental acerca do compromisso previamente assumido, atendendo o interesse de ambas as partes.

Embora com algumas possibilidades de sinergias para a implementação e manutenção do projeto de recuperação da cascalheira do Parque Recreativo Sucupira com a FUP, dado a área estar completamente degradada, a relação benefício/custo do projeto é questionável. Existem áreas, porém com um menor grau de degradação comparativamente a cascalheira do Parque Recreativo Sucupira, que têm sido alvo de lançamento irregular de lixo e entulhos na proximidade da FUP. 
Essas áreas poderiam ser recuperadas a um custo menor, podendo o recurso de recuperação a ser investido na cascalheira alcançar melhores resultados ambientais em caso de ser aplicado na recuperação dessas áreas. Portanto, recomenda-se uma nova negociação com o IBRAM no intuito de substituir a obrigação da UnB para a recuperação de uma área maior, porém com um grau de degradação menor.

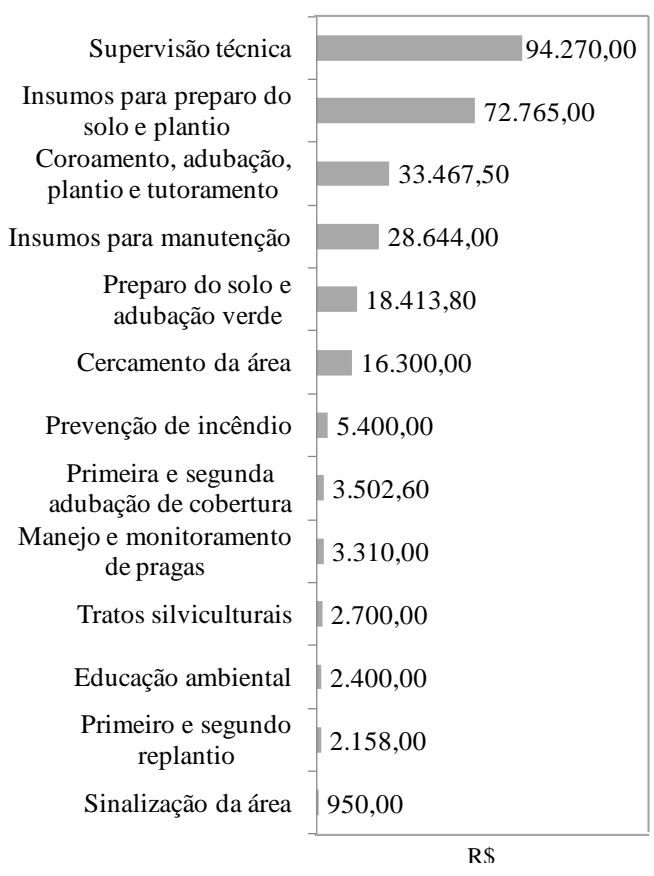

Figura 4. Resumo geral dos custos por atividade do projeto (em R\$).

Para a área de 5,37 ha da cascalheira do Parque Recreativo Sucupira, sugere-se que seja realizada alguma obra de infraestrutura para atender e atrair a comunidade como, por exemplo, a construção de uma pista de competição de ciclismo BMX. Esse projeto tem sido uma demanda de parte da comunidade local e não exigiria a ampliação do desmatamento e nem da pavimentação da área.

A importância de atrair a comunidade para a participação nas decisões das Unidades de Conservação (UCs) é apresentada por Pimbert e Pretty
(2000). Segundo esses autores, há um crescente reconhecimento que sem o envolvimento da população do entorno das UCs no planejamento, manejo e gestão das áreas preservadas, poucas são as chances de sucesso dos projetos para a conservação da biodiversidade e, como consequência, os custos de manejo se elevam.

\section{Conclusões}

O projeto de recuperação da cascalheira do Parque Recreativo Sucupira demanda uma rigorosa intervenção no preparo do solo e a necessidade de um plantio adensado de mudas, considerando espécies de Cerrado em estágios iniciais e finais de sucessão.

O período total do projeto é de seis anos, prevendo dois anos para cada fase: implementação, manutenção e monitoramento. As atividades previstas no projeto tomou como base o diagnóstico da área, bem como, se fundamentou em revisão de literatura sobre recuperação de área degradada decorrente de atividades de mineração.

O custo previsto para recuperar a cascalheira do Parque Recreativo Sucupira esteve de acordo com projetos para áreas com grau de degradação similar e que utilizaram técnica de recuperação semelhante, esses prevendo um custo de recuperação total por hectare acima de R\$ 50 mil. O principal custo previsto foi com a supervisão técnica do projeto, podendo esse ser reduzido se ficar a cargo dos servidores da UnB. Destacaram-se também os custos na fase de implantação do projeto, devido à compra de mudas nativas do cerrado e a recuperação física e química do solo.

Em caso de possíveis parcerias entre a Universidade de Brasília, órgãos governamentais da Região Administrativa de Planaltina e do IBRAM, é previsto sinergias na realização das atividades de recuperação e otimização na alocação de recursos, podendo reduzir os custos do projeto. Ainda assim, existem outras áreas degradas na proximidade da FUP que poderiam ser recuperadas com um custo menor e que apresentam uma relação custo/benefício mais atrativa quando 
comparado com a recuperação da cascalheira do Parque Recreativo Sucupira. Embora haja outras áreas que poderiam ser recuperadas com valor reduzido, o compromisso assumido pela UnB para receber a licença ambiental decorrente da construção do seu campus em Planaltina foi recuperar a cascalheira do Parque Recreativa Sucupira.

\section{Declaração de conflito de interesses}

Os autores declaram não haver conflito de interesses.

\section{Referências}

Almeida, L. F.; Lima, M. F.; Braga, M. S.; Mattos, C. N.; Kale, F. L. D. Diagnóstico de áreas potenciais para recuperação de área degradada, em região de extração de areia, com uso de sedimento de canal de adução de água e lodo de estação de tratamento de esgoto. Anais do X Simpósio Ítalo-Brasileiro de Engenharia Sanitária e Ambiental, Maceió, 2010.

Bernandes, M. C. Avaliação da cobertura da terra do Parque Recreativo Sucupira e de sua zona de influência direta. Brasília: Universidade de Brasília, 2013. (Trabalho de Conclusão de Curso).

BNDES - Banco Nacional de Desenvolvimento. Taxa de Juros a Longo Prazos - TJLP. 2016. Disponível em: $<$ http://www.bndes.gov.br/SiteBNDES/bndes/b ndes_pt/Ferramentas_e_Normas/Custos_Financ eiros/Taxa_de_Juros_de_Longo_Prazo_TJLP $>$. Acesso em: 05 abr. 2016.

Brasil. Lei no 8.666, de 21 de junho de 1993. Regulamenta o art. 37, inciso XXI, da Constituição Federal, institui normas para licitações e contratos da Administração Pública e dá outras providências. Disponível em: $<$ http://www.planalto.gov.

br/ccivil_03/leis/L8666cons.htm>. Acesso em: 05 abr. 2016.

Casarotto Filho, N.; Kopittke, B. H. Análise de investimentos. 11. ed. São Paulo: Atlas, 2010.

Cavalcante J. F. Emancipação e participação popular: a gestão participativa no Parque Recreativo Sucupira em Planaltina, DF. Universidade de Brasília. Brasília, 2010. (Dissertação de mestrado).

CEB - Companhia Energética de Brasília. Projeto de Recuperação da Torre de
Telecomunicação Colorado. Brasília: CEB, 2015. (Trabalho não publicado).

Corrêa, R. S. Recuperação de áreas degradadas pela mineração no Cerrado: manual para revegetação. 2. ed. Brasília: Universa, 2007.

Distrito Federal. Lei Complementar $n^{\circ}$ 265, de 14 de dezembro de 1999. Dispõe sobre a criação de Parques Ecológicos e de Uso Múltiplo no Distrito Federal. Disponível em: $<$ http://www.tc.df.gov.br/

SINJ/Arquivo.ashx?id_norma_consolidado $=520$ 94>. Acesso em: 05 abr. 2016.

Distrito Federal. Lei $\mathbf{n}^{\mathbf{0}}$ 1.318, de 23 de dezembro de 1996. Cria o Parque Recreativo Sucupira na Região Administrativa de Planaltina - RA VI. Disponível em: $<$ http://www.tc.df.gov.br/

SINJ/Arquivo.ashx?id_norma_consolidado $=492$ 72>. Acesso em: 05 abr. 2016.

EMBRAGEA - Empresa Brasileira de Gestão Ambiental Júnior. PRAD - Taquari, Chácara Riacho Doce. Brasília: EMBRAGEA, 2014. (Trabalho não publicado).

Furtini Neto, A. E. F.; Siqueira J. O.; Curi, N.; Moreira, F. M. S. Fertilization in native species reforestation. In: Gonçalves, J. L. M.; Benedetti, V. (Orgs.). Forest nutrition and fertilization. Piracicaba: Instituto de Pesquisas Florestais e Estudos Florestais, 2004. p. 342-388.

Gonçalves, J. L. M.; Stape, J. L.; Benedetti, V.; Fessel, V. A. G.; Gava, J. L. An evaluation of minimum and intensive soil preparation regarding fertility and tree nutrition. In: Gonçalves, J. L. M.; Benedetti, V. (Orgs.). Forest nutrition and fertilization. Piracicaba: Instituto de Pesquisas Florestais e Estudos Florestais, 2004. p. 10-60.

IBAMA - Instituto Brasileiro do Meio Ambiente e dos Recursos Naturais Renováveis. Planilha de custos para análise de PRAD (valores médios). Goiânia: IBAMA, Superintendência de Goiás, 2013. Disponível em: <http://supremoambiental. com.br/wpcontent/uploads/2014/08/Instru ção-Normativan.-004-IBAMA-2011-Termo-de-Referência-dePRAD-Planilha-de-Custos.pdf $>$. Acesso em: 19 mar. 2016.

IBGE - Instituto Brasileiro de Geografia e Estatística. Disponível em: $<$ http://www.ibge.gov.br>. Acesso em: 19 abr. 2017.

IBRAM - Instituto Brasília Ambiental. Disponível em: <http://www.ibram.df.gov.br>. Acesso em: 16 set. 2016. 
Kageyama, P.; Gandara, F. B. Restauração e conservação de ecossistemas tropicais. In: Cullen Jr., L.; Rudran, R.; Valladares-Padua, C. (Orgs.). Métodos de estudos em Biologia da Conservação: manejo da vida silvestre. Curitiba: Editora UFPR, Fundação o Boticário, 2004. p. 380-394.

Leite, L. L.; Castro, A. J. R. Situação dos planos de recuperação de áreas degradadas (PRAD) nos processos de licenciamento de cascalheiras no Distrito Federal. Anais do V Simpósio Nacional sobre Recuperação de Áreas Degradadas: Água e Biodiversidade, Belo Horizonte, 2002.

Leite, L. L.; Martins, C. R.; Haridasan, M. Propriedades físico-hídricas do solo de uma cascalheira e de áreas adjacentes com vegetação nativa de Campo Sujo e Cerrado no Parque Nacional de Brasília. Anais do Simpósio Nacional Recuperação de Áreas Degradadas, Curitiba, 1992. p. 390-399.

Lopes, A. S. Manejo: aspectos químicos. In: Pereira, P. P.; Ferreira, M. E.; Cruz, M. C. P. (Eds.). Solos altamente suscetíveis à erosão. Jaboticabal: FCAV-UNESP/SBCS, 1994. p. 90111.
Martins, S. V. Recuperação de áreas degradadas. Viçosa: Aprenda Fácil, 2009.

Oliveira, V. M. S. Panorama dos parques de Planaltina-DF: pressão antrópica sobre áreas verdes urbanas. Brasília: UnB, 2014. (Trabalho de Conclusão de Curso).

Pimbert, M. P.; Pretty, J. N. Parques, comunidades e profissionais: incluindo “participação” no manejo de áreas protegidas. In: Diegues, A. C. S. (Org.). Etnoconservação: novos rumos para a proteção da Natureza nos trópicos. São Paulo: Hucitec, NUPAUB-USP, 2000. p. 183-223.

Santos, E.; Gomes, A. L. Tecnologia de recuperação de áreas degradadas. Anais da III Exposição de Tecnologia Agropecuária Ciência para a Vida, SOBRADE, EMBRAPA, 2012.

Siqueira, J. O.; Curi, N.; Vale, F. R.; Ferreira, M. M.; Moreira, F. M. S. Aspectos de solos, nutrição vegetal e microbiologia na implantação de matas ciliares. Belo Horizonte: CEMIG, 1995.

Informação da Licença: Este é um artigo Open Access distribuído sob os termos da Licença Creative Commons Attribution, que permite uso irrestrito, distribuição e reprodução em qualquer meio, desde que a obra original seja devidamente citada. 
Anexo 1. Atividades e orçamento detalhado da fase de implantação.

\begin{tabular}{|c|c|c|c|c|c|}
\hline Atividade & Descrição & Unidade & Quantidade & $\begin{array}{c}\text { Preço } \\
\text { unitário } \\
\text { (R\$) }\end{array}$ & $\begin{array}{c}\text { Preço total } \\
\text { (R\$) }\end{array}$ \\
\hline \multirow{7}{*}{$\begin{array}{l}\text { Cercamento da } \\
\text { área }\end{array}$} & Estacas & Unid & 500 & 10,00 & $5.000,00$ \\
\hline & Esticador & Unid & 25 & 40,00 & $1.000,00$ \\
\hline & Grampo & $\mathrm{Kg}$ & 5 & 20,00 & 100,00 \\
\hline & Arame & Bolas & 20 & 365,00 & $7.300,00$ \\
\hline & Mão de obra & Diária & 10 & 250,00 & $2.500,00$ \\
\hline & $\begin{array}{c}\text { Transporte, alimentação e } \\
\text { ferramentas }\end{array}$ & Diária & 10 & 40,00 & 400,00 \\
\hline & \multicolumn{4}{|c|}{ Total } & $16.300,00$ \\
\hline \multirow{4}{*}{$\begin{array}{l}\text { Placas de } \\
\text { sinalização }\end{array}$} & Placa de sinalização & Unidade & 1 & 810,00 & 810,00 \\
\hline & Placa $30 \times 50 \mathrm{~cm}$ & Diária & 1 & 100,00 & 100,00 \\
\hline & Mão de obra & Diária & 1 & 40,00 & 40,00 \\
\hline & \multicolumn{4}{|c|}{ Total } & 950,00 \\
\hline \multirow{3}{*}{$\begin{array}{c}\text { Manejo de } \\
\text { praga antes do } \\
\text { plantio }\end{array}$} & $\begin{array}{l}\text { Iscas formicidas e } \\
\text { cupinicida }\end{array}$ & $\mathrm{R} \$ / \mathrm{kg}$ & 10 & 18,00 & 180,00 \\
\hline & Mão de obra & Diária & 3 & 100,00 & 300,00 \\
\hline & \multicolumn{4}{|c|}{ Total } & 480,00 \\
\hline \multirow{6}{*}{$\begin{array}{l}\text { Insumos para o } \\
\text { preparo do solo } \\
\text { e o plantio }\end{array}$} & Calcário - Dolomítico & $\mathrm{R} \$ / \mathrm{kg}$ & 2.300 & 1,55 & $3.565,00$ \\
\hline & $\begin{array}{c}\text { Adubo Químico NPK } \\
4: 14: 8\end{array}$ & $\mathrm{R} \$ / \mathrm{kg}$ & 1.500 & 1,20 & $1.800,00$ \\
\hline & $\begin{array}{l}\text { Adubo orgânico para o } \\
\text { plantio }\end{array}$ & $\mathrm{R} \$ / \mathrm{m}^{3}$ & 180 & 120,00 & $21.600,00$ \\
\hline & Mudas para Plantio & Unidade & 8.950 & 5,00 & $44.750,00$ \\
\hline & Isca formicida e cupinicida & $\mathrm{R} \$ / \mathrm{kg}$ & 25 & 18,00 & 450,00 \\
\hline & \multicolumn{4}{|c|}{ Total } & $72.765,00$ \\
\hline \multirow{7}{*}{$\begin{array}{c}\text { Preparo do solo } \\
\text { e adubação } \\
\text { verde }\end{array}$} & $\begin{array}{c}\text { Trator de pneus }+ \\
\text { escarificador }\end{array}$ & $\mathrm{R} \$ / \mathrm{h}$ & 32 & 200,00 & $6.400,00$ \\
\hline & $\begin{array}{c}\text { Abertura de sulcos com } \\
\text { sulcador }\end{array}$ & $\mathrm{R} \$ / \mathrm{h}$ & 13 & 150,00 & $1.950,00$ \\
\hline & $\begin{array}{c}\text { Adubo Químico NPK } \\
4: 14: 8 \\
\end{array}$ & $\mathrm{R} \$ / \mathrm{kg}$ & 1.074 & 1,20 & $1.288,80$ \\
\hline & Calcário - Dolomítico & $\mathrm{R} \$ / \mathrm{kg}$ & 4.600 & 1,55 & $7.130,00$ \\
\hline & Adubação verde & $\mathrm{Kg}$ & 430 & 1,50 & 645,00 \\
\hline & Mão de obra & Diária & 10 & 100,00 & $1.000,00$ \\
\hline & \multicolumn{4}{|c|}{ Total } & $18.413,80$ \\
\hline \multirow{8}{*}{$\begin{array}{l}\text { Coroamento, } \\
\text { adubação, } \\
\text { plantio e } \\
\text { tutoramento }\end{array}$} & Coroamento & R\$/hora & 25 & 120,00 & $3.000,00$ \\
\hline & $\begin{array}{c}\text { Abertura de sulcos com } \\
\text { sulcador } \\
\end{array}$ & Hora & 13 & 150,00 & $1.950,00$ \\
\hline & $\begin{array}{c}\text { Coveamento } 45 \mathrm{~cm} \text { x } 45 \\
\mathrm{~cm} \text { x } 60 \mathrm{~cm} \\
\end{array}$ & $\mathrm{R} \$ /$ cova & 8.950 & 0,90 & $8.055,00$ \\
\hline & Adubação & $\mathrm{R} \$ /$ cova & 8.950 & 0,20 & $1.790,00$ \\
\hline & Tutor $1,6 \mathrm{~m}$ & Unidade & 8.950 & 1,35 & $12.082,50$ \\
\hline & Plantio das mudas & $\mathrm{R} \$ /$ cova & 8.950 & 0,20 & $1.790,00$ \\
\hline & $\begin{array}{c}\text { Transporte, alimentação e } \\
\text { ferramentas } \\
\end{array}$ & Diária & 120 & 40,00 & $4.800,00$ \\
\hline & \multicolumn{4}{|c|}{ Total } & $33.467,50$ \\
\hline \multirow{5}{*}{$\begin{array}{l}\text { Supervisão } \\
\text { Técnica de } \\
\text { profissional } \\
\text { habilitado }\end{array}$} & Responsável técnico & Hora & 305 & 122,00 & $37.210,00$ \\
\hline & Profissional habilitado & Hora & 30 & 180,00 & $5.400,00$ \\
\hline & Transporte e alimentação & Diária & 34 & 40,00 & $1.360,00$ \\
\hline & Taxa de administração & Unidade & 1 & $3.000,00$ & $3.000,00$ \\
\hline & \multicolumn{4}{|c|}{ Total } & $46.970,00$ \\
\hline
\end{tabular}


Anexo 2. Atividade e orçamento detalhado da fase de manutenção e monitoramento.

\begin{tabular}{|c|c|c|c|c|c|}
\hline Atividade & Descrição & Unidade & Quantidade & $\begin{array}{c}\text { Preço } \\
\text { unitário } \\
\text { (R\$) }\end{array}$ & $\begin{array}{c}\text { Preço } \\
\text { total (R\$) }\end{array}$ \\
\hline \multirow{6}{*}{$\begin{array}{l}\text { Insumos para } \\
\text { manutenção }\end{array}$} & Calcário - Dolomítico & $\mathrm{R} \$ / \mathrm{kg}$ & 1.000 & 1,55 & $1.550,00$ \\
\hline & $\begin{array}{c}\text { Adubo Qumico NPK } \\
4: 14: 8\end{array}$ & $\mathrm{R} \$ / \mathrm{kg}$ & 1.000 & 1,20 & $1.200,00$ \\
\hline & $\begin{array}{c}\text { Adubo orgânico para o } \\
\text { plantio }\end{array}$ & $\mathrm{R} \$ / \mathrm{m}^{3}$ & 140 & 120,00 & $16.800,00$ \\
\hline & Mudas para Plantio & Unidade & 1.790 & 3,00 & $5.370,00$ \\
\hline & $\begin{array}{l}\text { Isca formicida e } \\
\text { cupinicida }\end{array}$ & $\mathrm{R} \$ / \mathrm{kg}$ & 8 & 18,00 & 144,00 \\
\hline & \multicolumn{4}{|c|}{ Total } & $28.644,00$ \\
\hline \multirow{3}{*}{$\begin{array}{l}1^{\text {a }} \text { Adubação de } \\
\text { cobertura }\end{array}$} & Adubação & $\mathrm{R} \$ /$ cova & 4.475 & 0,20 & 895,00 \\
\hline & $\begin{array}{c}\text { Transporte, alimentação } \\
\text { e ferramentas }\end{array}$ & Diária & 32 & 40,00 & $1.280,00$ \\
\hline & \multicolumn{4}{|c|}{ Total } & $2.175,00$ \\
\hline \multirow{3}{*}{$\begin{array}{l}2^{a} \text { Adubação de } \\
\text { cobertura }\end{array}$} & Adubação & $\mathrm{R} \$ /$ cova & 2.238 & 0,20 & 447,60 \\
\hline & $\begin{array}{c}\text { Transporte, alimentação } \\
\text { e ferramentas }\end{array}$ & Diária & 22 & 40,00 & 880,00 \\
\hline & \multicolumn{4}{|c|}{ Total } & $1.327,60$ \\
\hline \multirow{3}{*}{$1^{\circ}$ Replantio } & Plantio das Mudas & $\mathrm{R} \$ /$ cova & 448 & 0,20 & 89,60 \\
\hline & $\begin{array}{c}\text { Transporte, alimentação } \\
\text { e ferramentas }\end{array}$ & Diária & 15 & 40,00 & 600,00 \\
\hline & \multicolumn{4}{|l|}{ 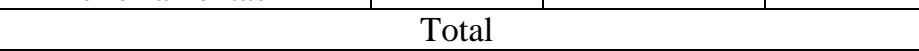 } & 689,60 \\
\hline \multirow{3}{*}{$2^{\circ}$ Replantio } & Plantio das mudas & $\mathrm{R} \$ /$ cova & 1.342 & 0,20 & 268,40 \\
\hline & $\begin{array}{c}\text { Transporte, alimentação } \\
\text { e ferramentas }\end{array}$ & Diária & 30 & 40,00 & $1.200,00$ \\
\hline & \multicolumn{4}{|c|}{ Total } & $1.468,40$ \\
\hline \multirow{4}{*}{$\begin{array}{l}\text { Monitoramento } \\
\text { de pragas }\end{array}$} & $\begin{array}{l}\text { Iscas formicidas e } \\
\text { cupinicida }\end{array}$ & $\mathrm{R} \$ / \mathrm{kg}$ & 35 & 18,00 & 630,00 \\
\hline & $\begin{array}{c}\text { Transporte, alimentação } \\
\text { e ferramentas }\end{array}$ & Diária & 25 & 40,00 & $1.000,00$ \\
\hline & Mão de obra & Diária & 12 & 100,00 & $1.200,00$ \\
\hline & \multicolumn{4}{|c|}{ Total } & $2.830,00$ \\
\hline \multirow{3}{*}{$\begin{array}{c}\text { Tratos } \\
\text { silviculturais } \\
\text { (coroamento e } \\
\text { roçadas) }\end{array}$} & $\begin{array}{c}\text { Roçagem com roçadeira } \\
\text { costal }\end{array}$ & $\mathrm{R} \$ / \mathrm{h}$ & 50 & 50,00 & $2.500,00$ \\
\hline & $\begin{array}{c}\text { Transporte, alimentação } \\
\text { e ferramentas }\end{array}$ & Diária & 5 & 40,00 & 200,00 \\
\hline & \multicolumn{4}{|c|}{ Total } & $2.700,00$ \\
\hline \multirow{3}{*}{$\begin{array}{l}\text { Prevenção a } \\
\text { incêndio }\end{array}$} & $\begin{array}{c}\text { Roçagem com roçadeira } \\
\text { costal }\end{array}$ & $\mathrm{R} \$ / \mathrm{h}$ & 100 & 50,00 & $5.000,00$ \\
\hline & $\begin{array}{c}\text { Transporte, alimentação } \\
\text { e ferramentas }\end{array}$ & Diária & 10 & 40,00 & 400,00 \\
\hline & \multicolumn{4}{|c|}{ Total } & $5.400,00$ \\
\hline \multirow{3}{*}{$\begin{array}{l}\text { Educação } \\
\text { ambiental }\end{array}$} & $\begin{array}{l}\text { Impressão de folheto } 10 \\
\text { x } 15 \mathrm{~cm}\end{array}$ & Unidade & 5.000 & 0,28 & $1.400,00$ \\
\hline & $\begin{array}{l}\text { Mão de obra para } \\
\text { panfletar }\end{array}$ & Diária & 20 & 50,00 & $1.000,00$ \\
\hline & \multicolumn{4}{|c|}{ Total } & $2.400,00$ \\
\hline \multirow{4}{*}{$\begin{array}{c}\text { Supervisão } \\
\text { técnica de } \\
\text { profissional } \\
\text { habilitado }\end{array}$} & Responsável técnico & Hora & 300 & 122,00 & $36.600,00$ \\
\hline & Profissional habilitado & Hora & 15 & 180,00 & $2.700,00$ \\
\hline & $\begin{array}{c}\text { Transporte, alimentação } \\
\text { e ferramentas }\end{array}$ & Diária & 50 & 40,00 & $2.000,00$ \\
\hline & \multicolumn{4}{|c|}{ Total } & $41.300,00$ \\
\hline
\end{tabular}

